\title{
Prevalence of Childhood Developmental Delay in Child under 5 Years Old Living in Ulaanbaatar
}

\author{
Narantuya B, Chimedsuren $\mathrm{O}^{*}$ and Lkhagvasuren Ts
}

School of Public Health, Mongolian National University of Medical Science, Ulaanbaatar, Mongolia

*Corresponding Author: Chimedsuren O, School of Public Health, Mongolian National University of Medical Science, Ulaanbaatar, Mongolia, Tel: +97611328924; E-mail: chimedsuren@ mnums.edu.mn

Received: 21 August 2017; Accepted: 31 August 2017; Published: 04 September 2017

\section{Abstract}

The Background: Children's development and childhood disability are a public health priority due to their consequences affecting quality of life and productivity not only of the affected children but also of the families and populations as a whole. WHO and the World Bank estimate that more than a billion people live with some form of disability, which equates to approximately $15 \%$ of the world's population. Citing the Global Burden of Disease study of 2004, the World Report further estimates that amongst those aged 0-14 years, roughly $5.1 \%$ of all children (93 million) live with a 'moderate or severe' disability and $0.7 \%$, or 13 million children live with severe difficulties. Many children younger than 5 years in developing countries are exposed to multiple risks, including poverty, malnutrition, poor health, and other risks, which affect their cognitive, motor, and social emotional development. There are a few researches and national statistics on the childhood delay and disabilities of under 5 years children in Mongolia.

Objective: The main objective of the study was to screen childhood developmental delay under 5 years children in Ulaanbaatar, Mongolia.

Methods: Ten questions screening method was used in order to detect developmental delay in children of chosen age in Ulaanbaatar, Mongolia.

Results: A total of 1971 (25.8 percent) of the 7908 children surveyed had positive screening results on the Ten Questions instrument and 5937 of those children screening negatively. By age group 9 months 16.7 percent, 18month-old 16.03\%, 2 years old (17.4\%) 3 years old 1255 (15.87\%), 4 years old 1303 (16.47\%) and 5 years old, 17.5 percent revealed positive results. By types of delays there were $8 \%$ motor delay, $8.2 \%$ hearing, $4.2 \%$ vision, $7.7 \%$ 
cognitive delay and $10.5 \%$ speech and language. The developmental delay was observed to be higher (1163) in boys $(16.3 \%)$ than in girls.

Conclusion: Out of 7908 children aging from 9 months to 5 years old, $25.8 \%$ were detected to be developmentally delayed.

Keywords: Developmental delay; Ten questions screening

\section{Introduction}

This research has taken place in the Ulaanbaatar city, the capital of Mongolia where most of the population resides and has comprehended children under 5 years of age. Children were divided into 6 groups of age and total of 7908 children were involved. The research was conducted using the Ten Questions Screening, a recommended method by WHO and UNICEF and co-operating with a specialist team. The results showed that $25.8 \%$ of the total children were found to have developmental delay.

\section{Material and Methods}

\subsection{Children}

Ten questions screening method was used in order to detect developmental delay in children of chosen age in Ulaanbaatar, Mongolia. Children were divided into 6 groups of age -9 months, 18 months, 2 years old, 3 years old, 4 years old, 5 years old. Face to face interview with the parent or care giver was held using questions containing the Ten questions screening method. Information was gathered from the Notebook of Mother and Child's Health, when necessary. Sex of the children involved was set to 1:1 ratio. The child's current height and weight was measured and examination, interview took around 10-15 minutes [1-3]. 80\% of the care givers of 7908 children were their mothers.

\subsection{Statistical analysis}

The data was entered, cleaned and stat analysis twice using the Epidata program, afterwards the Stata program provided the results in statistics. Potential cases of developmental delay in children, certain factors of the population, such as the child's age group, sex, citizenship were taken into account. The results were expressed in percentage [4]. In order to differentiate the potential cases of developmental delay in children quantitatively, define the spread as normal and abnormal. When the spread is normal, the student's $t$ test (parameter method) is carried out. When the spread was abnormal, or hard to diagnose, the non-parameter method was conducted. On the other hand, in order to detect it qualitatively, the Fisher method and the xi square method was used. Statistical materiality was found material when below $0.05[5,6]$.

\section{Results}

In this research 7908 children aged from 9 months to 5 years old participated. Precisely, 1323 children of 9 months old, 1268 of 18 months old, 1375 of 2 years old, 1255 of 3 years old, 1303 of 4 years old and lastly, 1384 of 5 years 
old children. Among them, 4025 boys, which equals to $50.9 \%$ of the total population; 3883 girls taking up the rest $49.1 \%$.

To break this number in means of age groups: $16.7 \%$ of 9 months old newborns, $16.3 \%$ of 18 months old babies, $17.4 \%$ of 2 years old children, $15.87 \%$ of 3 years old, $16.47 \%$ of 4 years old, $17.5 \%$ of 5 years old children were diagnosed to have developmental delay. Of the total 7908 children involved, 1971 (25.8\%) children were discovered to have developmental delay according to the Ten questions screening method (Table 1). In means of skills on average of all age groups: motor skills risk $8 \%$, hearing skills risk $8.2 \%$, vision skills risk $4.2 \%$, cognitive skills risk $7.7 \%$ and lastly, linguistic skills risk $10.5 \%$ (Table 2). From the 7908 children, total $8 \%$ of them were found to have potential developmental delay in motor skills, which is likely to decrease as children grow older. Among the children of 9 months, 18 months and 5 years old motor skills developmental delay acquired 12.9\%, 11.1\%, 7.2\% respectively, which is statistically material as they were significantly higher than in children of other age groups. From the 7908 children, $8.2 \%$ were detected to have hearing developmental delays and were random throughout the age groups. Among the children of 18 months, 4 years and 5 years old, the hearing developmental delay was $11.7 \%$, $9.6 \%, 8.7 \%$, whereas children of 9 months, 2 years old, 3 years old were $8.4 \%, 6.8 \%, 3.8 \%$ respectively. From the total 7908 children, $4.2 \%$ were detected to have vision developmental delay. The proportion was higher in the younger age groups and seemed to be increasing in children from 9 months old to 2 years old children. Among children from 3-5 years old, the percentage was 2.8, 3.0, 3.1 respectively. From the 7908 children, $7.7 \%$ were discovered to have potential developmental delay in cognitive skills. 3 years old children had the least percentage of $2.7 \%$, whereas the children of 5 years old had the highest risk of $14.0 \%$. Among the 7908 children, $10.4 \%$ were found to have potential developmental delay in their speech skills and it was random throughout the age groups. From 9 months to 2 years old age groups, the risk was likely to decrease with the percentages being $14.4 \%$, $11.9 \%$, $8.6 \%$ respectively. However, the children of 3 years old had the highest risk of $10.5 \%$.

\begin{tabular}{|l|l|}
\hline Age group & Number of cases (\%) \\
\hline 9 months & $329(16.7)$ \\
\hline 18 months & $321(16.3)$ \\
\hline 2 years & $343(17.4)$ \\
\hline 3 years & $308(15.87)$ \\
\hline 4 years & $325(16.47)$ \\
\hline 5 years & $345(17.5)$ \\
\hline Total & $1971(25.8)$ \\
\hline
\end{tabular}

Table 1: Screening results in Ulaanbaatar capital city of Mongolia.

\begin{tabular}{|l|l|}
\hline Types of disabilities & Number of cases (\%) \\
\hline Motor & $633(8)$ \\
\hline Hearing & $648(8.2)$ \\
\hline Vision & $332(4.2)$ \\
\hline Cognitive & $609(7.7)$ \\
\hline Speech & $830(10.5)$ \\
\hline Total & $1971(25.8)$ \\
\hline
\end{tabular}

Table 2: Types of developmental delays among the selected children in Ulaanbaatar capital city of Mongolia. 


\section{Discussion}

Initially, 8730 children were inspected in order to detect developmental delays in children of Ulaanbaatar using the Ten Questions Screening method. However, only 7908 of them met the criteria for the research. Thornburn M J, Durkin M S, Belmont L and their team have invented the Ten questions Screening method in 1992 [7]. The ten questions screening is a simple method based on a population, by taking information on the child from their care giver. This method is relatively cost effective, as it does not require special machines, doctors and researchers and is commonly used in developing countries. In this research 7908 children aged from 9 months to 5 years old participated. Precisely, 1323 children of 9 months old, 1268 of 18 months old, 1375 of 2 years old, 1255 of 3 years old, 1303 of 4 years old and lastly, 1384 of 5 years old children were examined under the Ten Questions Screening method. The UNICEF has conducted a research to detect developmental delay in children from 50 countries aged from 2-9 years old. 4204 Mongolian children were involved. This research has also used the Ten questions screening method and $15.6 \%$ of those children were found to be developmentally delayed. Whereas in children from Laos, it was $7.9 \%$, from Thailand $10.4 \%$, from Bangladesh $17.1 \%$. As you can see, in children from Bangladesh and Mongolia, the developmentally delayed children were almost 1.5 times as much as in the other countries. Our research in 2017 showed that from 7908 children, 25.8\% were developmentally delayed, which is 10\% than the number from the above figure [8-11]. This could be explained in two ways: parents were very much sensitive to the questions, answering every question to be positive, or the doctors examining and diagnosing the children. Between the 6 age groups, children of 9-18 months old had the highest risk of 31.7-33.2\%, whereas 3 years old children's risk was at $17.2 \%$. Sexually, we noticed a statistical materiality. Researchers Howaida A, Nowno have conducted a study among 450 children living in country-side of Saudi Arabia Riyal during 2010-2011. The results showed that 33.1\% of total developmental delay were linguistic skills, $20.4 \%$ were in cognitive, vision $13.1 \%$, hearing $27.3 \%$. Our research has resulted in the following: motor skills risk $8.0 \%$, hearing skills risk $8.2 \%$, vision skills risk $4.2 \%$, cognitive skills risk $7.7 \%$, linguistic skills risk $10.5 \%$. These results are relatively low compared to the figures above. Diagnosing the spread in children, particularly infants can be complicated. The reason is researches and doctors have not come up with a united definition of developmental delay in children. Also, because the cognitive and motor skills of children develop very fast, detecting, screening and researching of children's developmental delay always comes with burdens. Besides this, the definition of children's developmental delay differentiates according to the medical development in the countries as well as the people and environment $[12,13]$.

\section{Limitations}

As any other research based on cross sectional studies screening test, discovering the relation of the factors resulting in developmental delay was impossible with this research. Our results, indicate that among children of all age groups, cognitive, linguistic and hearing skills were exposed to higher risk of being delayed. Detecting a child's developmental delay in the early stages is critical to rehabilitation treatment being successful. Therefore, studying the sensitive and special effects of the Ten questions screening method is of vital importance in order to detect developmental delay in children of Mongolia. 


\section{Conclusion}

This screening identified a significant burden of childhood developmental delay in an urban area of Mongolia, with $25.8 \%$ of under 5 years aged children. Furthermore, nationwide screening and clinical evaluation of developmental delay and disability are needed.

\section{References}

1. Center of Health Development. Statistic of Health (2016).

2. National Statistical Office. Population and Housing Census (2010).

3. Capital City Health Department. Capital health and statistical indicators of the population (2016).

4. Ertem IO, Dogan DG, Gok CG, et al. A guide for monitoring child development in low- and middleincome countries. Pediatrics 121 (2008): e581-589.

5. Examining early child development in low-income countries: a toolkit for the assessment of children in the first five years of life. Washington, World Bank (2009).

6. Walker SP1, Wachs TD, Gardner JM, et al. Child development: risk factors for adverse outcomes in developing countries. Lancet 369 (2007): 145-147.

7. Thorburn M, Desai P, Paul TJ, et al. Identification of childhood disability in Jamaica: the ten question screen. Int J Rehabil Res 15 (1992): 115-127.

8. Mung'ala-Odera V, Meehan R, Njuguna P, et al. Prevalence and risk factors of neurological disability and impairment in children living in rural Kenya. Int J Epidemiol 35 (2006): 683-688.

9. Introduction to OAE and Tympanometer. http://MAClusoptix.com.

10. Llewellyn G, Emerson Ros Madden E, Honey A. The Well-Being Of Children With Disabilities In The Asia Pacific Region: an Analysis of Unicef Mics 3 Survey Data from Bangladesh, Lao Pdr, Mongolia and Thailand.

11. Krakow JB, Kopp CB. The effects of developmental delay on sustained attention in young children. Child Dev 54 (1983): 1143-1155.

12. Thorburn MJ, Desai P, Paul TJ. Service needs of children with disabilities in Jamaica. International Journal of Rehabilitation Research 15 (1992): 31-38.

13. Zaman S, Khan N, Islam S, et al. Validity of the Ten Questions for screening serious childhood disability: results from urban Bangladesh. International Journal of Epidemiology 19 (1990): 613-620. 